\title{
Integrated Treatment of Breast Cancer-related Lymphedema: A Descriptive Review of the State of the Art
}

\author{
PAOLO MARCHICA ${ }^{1 *}$, SALVATORE D'ARPA $^{2 *}$, STEFANO MAGNO $^{3}$, CRISTINA ROSSI $^{3}$, LUANA FORCINA $^{3}$, \\ VITA CAPIZZI $^{2}$, SEBASTIANO OIENI $^{2}$, CARMELA AMATO $^{4}$, DARIO PIAZZA ${ }^{5}$ and VITTORIO GEBBIA ${ }^{5,6}$ \\ ${ }^{1}$ Plastic Surgery Unit, University of Padua, Padua, Italy; \\ ${ }^{2}$ Plastic Surgery and Breast Unit, La Maddalena Clinic for Cancer, Palermo, Italy; \\ ${ }^{3}$ Center for Integrative Oncology, Fondazione Policlinico Universitario A. Gemelli IRCCS, Rome, Italy; \\ ${ }^{4}$ Serena a Palermo Association, Palermo, Italy; \\ ${ }^{5}$ GSTU Foundation for Cancer Research, Palermo, Italy; \\ ${ }^{6}$ Integrative Medicine in Oncology Program, Medical Oncology Unit, \\ La Maddalena Clinic for Cancer, Palermo, Italy
}

\begin{abstract}
Background/Aim: Upper limb breast cancerrelated lymphedema $(B C R L)$ is a chronic and severe condition affecting a significant percentage of breast cancer survivors. Even though its physiopathology is well-known, there is no worldwide consensus on BCRL evaluation and a goldstandard treatment. This narrative review aims at providing a brief descriptive overview with regard to BCRL treatment modalities. Materials and Methods: We conducted a literature search within the PubMed database, and 33 articles out of 56 were selected, including reviews, systematic reviews, and meta-analyses aiming find the most updated evidence regarding BCRL treatment modalities. Results: Physical exercise (aerobic exercise, resistance exercise, aquatic therapy), bandages, and intermittent pneumatic compression were shown to be most effective in BCRL patients, in terms of swelling reduction in the acute-intensive phase. Furthermore, physical exercise was beneficial also as a maintenance tool. Manual lymphatic drainage demonstrated efficacy in
\end{abstract}

This article is freely accessible online.

*These Authors contributed equally to the study.

Correspondence to: Prof. Vittorio Gebbia, Medical Oncology Unit, La Maddalena Cancer Center, and PROMISE Department University of Palermo, Via S. Lorenzo, 312/D, 90146 Palermo, Italy. Tel: +39 330696205, e-mail: vittorio.gebbia@gmail.com

Key Words: Breast cancer-related lymphedema, physical therapy, physical exercise, surgery, photo-biomodulation therapy, complementary medicine, review. preventing secondary lymphedema if applied immediately after breast cancer surgery or in early phases of BCRL or as a maintenance tool. Complementary procedures such as acupuncture, reflexology, yoga and photo-biomodulation therapy did not show conclusive results in BCRL treatment. Surgery was shown effective in managing symptoms (liposuction), preventing (lymphaticovenular anastomosis) and treating BCRL (vascularized lymph node transfer). Conclusion: BCRL is still a challenging condition either for breast cancer survivors and clinicians, deeply impacting patient functioning and quality of life. Due to the lack of globally accepted criteria in evaluating BCRL, to date a gold standard treatment for this widespread issue is still needed.

Improved survival rates in breast cancer patients contribute to an increased number of survivors complaining of upper limb Breast Cancer-Related Lymphedema (BCRL), which is a secondary lymphedema after surgery and radiation therapy (1). BCRL is a common complication occurring after lymph node dissection for breast or upper limb tumors (e.g., melanoma), and it is generally caused by an excessive accumulation of protein-rich fluid (lymph) in tissue extracellular spaces that causes transient or persistent soft tissue swelling (2). Up to $30 \%$ (3-5) of breast cancer survivors, may suffer from BCRL and its physical and psychological consequences such as: pain, pitting edema, upper limb heaviness and discomfort, decreased range of motion of the affected joints, recurrent skin infections and ulcers, elephantiasis, cutaneous angiosarcoma, depression, anxiety, body image-related disorder. Quality of life (QoL) is dramatically worsened by BCRL. 
Lymphedema (LYE) might be defined as "an increase of more than $10 \%$ in volume between the abnormal and normal arm" or "a difference of more than $200 \mathrm{ml}$ in arm volume or more than $20 \mathrm{~mm}$ in the circumference between the abnormal and normal arm" (6). All variants of LYE stem from an imbalance between production and drainage of protein-rich fluid, i.e., lymph. Secondary LYE is a consequence of a primary condition that does not directly impair lymphatic function and is the most frequently occurring condition. Primary LYE may be caused by a congenital dysfunction or anomaly of the lymphatic system, and it may be sporadic or hereditary or syndrome-associated and is less common $(7,8)$ than secondary $\operatorname{LYE}(9)$.

Secondary LYE finds its roots in obstruction or disruption of the lymphatic system due to cancer, radiation therapy, chronic venous insufficiency, surgery, trauma, or infections. Wuchereria bancrofti, responsible for filariasis, is the most common cause of secondary LYE worldwide (10).

Some risk factors participate in developing secondary LYE, such as obesity and pathological BMI, chemotherapy, the number of lymph nodes removed $(1,11,12)$. Some authors advocated physical exercise, but this theory has been rejected, as discussed below $(13,14)$. However, predisposing factors have not been yet identified. Despite older literature claiming the healthy state of the unaffected side, recent studies advocate the existence of differences between the arms' drainage function in the absence of any cancer or surgical treatment. More specifically, an unaffected lymph node side that non dissected may not be considered "normal" and presenting a slower tracer appearance time. Such differences in lymphatic function between the two limbs may predispose to LYE development (15).

International Society of Lymphology (ISL) classified the limb LYE in 4 stages: stage 0 to indicate subclinical or latent limb LYE with no evident volume gain and swelling but an initially impaired lymphatic network; stage I to indicate mild LYE with visible transient limb swelling and volume gain but with the possibility to be reduced with limb elevation; stage II to indicate non-reducible LYE with poor pitting edema and little to no response with limb elevation, as an indicator of tissue changes; stage III to indicate overt LYE with tissue changes such as fat and tissue fibrosis, hypertrophic thickened skin and limb deformities up to lymphostatic elephantiasis with absent pitting of edema (16).

Diagnosis of LYE is made by physical examination and is aided by linear circumference measurements or volumetric arm measurements based on water displacement. Advanced staging tools are indocyanine green lymphography, US and MRI, lymphoscintigraphy, lymphography, LASER scanning, bioimpedance spectroscopy (L-Dex score or lymphoedema index), perometry and tonometry (17).

Early detection and treatment on BCRL may reduce chronic BCRL rates by $>50 \%(18,19)$. Together with the increase of BCRL, the need for treatment is rising. However, BCRL is considered a chronic disease, and its management aims at disease control, prevention of complications and limb function preservation (20). Some medical and surgical solutions have been proposed, including physical exercise and treatment related to Complete (or Complex) Decongestive Therapy (CDT), medical treatment, surgery, complementary and integrative therapies. Here we present a review of literature regarding the state of the art of BCRL treatment in the last five years, with a brief discussion for each modality and its effectiveness in BCRL management.

\section{Materials and Methods}

This review aims at analyzing and discussing current knowledge on BCRL based on the last five years-literature. The review was conducted by search within the PubMed database. The authors (PM and SD) independently searched the past studies in the last five years using the following medical subject heading (MeSH) terms and free text words: "breast" AND "cancer" AND "lymphedema" AND "treatment." The following filters were applied: "Clinical Trial", "Meta-Analysis", "Randomized Controlled Trial", "Review", "Systematic Review", "in the last 5 years", "English", "Systematic Reviews", "MEDLINE". Our initial search yielded 56 studies, 23 of which were deemed not to be relevant after screening the titles and the abstract content because they dealt with other topics than BCRL treatment. Afterward, the reviewers screened the full text of the remaining 33 studies and extracted the recommendations that emerged from these papers. The authors discussed any discrepancies before including the conclusive evidence in this paper. Single casereports and case-series and single RCT were not considered.

\section{Results}

The authors displayed 56 articles after the research. Among them, only 33 papers were found relevant to the BCRL treatment topic, as shown in Table I. Manual Lymphatic Drainage (MLD) was discussed in 7 reports, bandage and garments roles were investigated in 2 different papers. Only one paper discussed Kinesio taping and intermittent pneumatic compression. Five articles from Eastern authors described the role of acupuncture. Most articles focused on physical exercise (14 papers on 23), evidencing the prominent and widespread part of physical activity in the treatment of BCRL. Surgical treatment of BCRL was discussed in only four scientific works, suggesting that surgery is not universally considered as a first-choice option in the treatment of BCRL yet. Four articles investigated the role of the emerging photo-biomodulation therapy. Finally, five articles discussed the role of complementary alternative medicine (yoga, reflexology).

Twenty-three articles (Table II) were not relevant to the aim of this work as they concerned topics other than the treatment of BCRL, such as epidemiology, comorbidities and impact of BCRL, diagnostic studies, the effect of 
Table I. Articles found relevant to BCRL treatment.

\begin{tabular}{|c|c|c|c|}
\hline Topic & Author & Year & Type \\
\hline \multirow[t]{7}{*}{ MLD } & Jang et al. (81) & 2020 & Systematic review and meta-analysis \\
\hline & Olsson Möller et al. (27) & 2019 & Systematic review \\
\hline & Jeffs et al. (32) & 2018 & Systematic review \\
\hline & Müller et al. (26) & 2018 & Systematic review \\
\hline & Smile TD et al. (31) & 2018 & Systematic review \\
\hline & D’Egidio et al. (33) & 2017 & Systematic review \\
\hline & Shao et al. (28) & 2017 & Systematic review \\
\hline \multirow[t]{2}{*}{ Bandage and garments } & Olsson Möller et al. (27) & 2019 & Systematic review \\
\hline & Rogan et al. (35) & 2016 & Systematic review and meta-analysis \\
\hline Kinesio Taping & Kasawara et al. (38) & 2018 & Meta-analysis \\
\hline IPC & Rogan et al. (35) & 2016 & Systematic review and meta-analysis \\
\hline \multicolumn{4}{|l|}{ Physical Exercise } \\
\hline \multirow[t]{5}{*}{ Resistance exercise } & Montaño-Rojas et al. (49) & 2020 & Systematic review \\
\hline & Hasenoehrl et al. (50) & 2020 & Systematic review and meta-analysis \\
\hline & Hasenoehrl et al. (46) & 2020 & Systematic review \\
\hline & Nelson (52) & 2016 & Systematic review \\
\hline & Keilani et al. (47) & 2016 & Systematic review \\
\hline Nordic walking & Sánchez-Lastra et al. (45) & 2019 & Systematic review \\
\hline Resistance exercise, yoga & Olsson Möller et al. (27) & 2019 & Systematic review \\
\hline \multirow{2}{*}{$\begin{array}{l}\text { Aerobic exercise, resistance } \\
\text { exercise, stretching }\end{array}$} & Panchik et al. (43) & 2019 & Systematic review \\
\hline & Furmaniak et al. (39) & 2016 & Systematic review \\
\hline \multirow[t]{2}{*}{ Resistance exercise, aquatic therapy } & Baumann et al. (42) & 2018 & Systematic review \\
\hline & Yeung et al. (53) & 2018 & Systematic review and meta-analysis \\
\hline \multirow[t]{3}{*}{ Non-specific physical exercise } & D'Egidio et al. (33) & 2017 & Systematic review \\
\hline & Rogan et al. (35) & 2016 & Systematic review and meta-analysis \\
\hline & Runowicz et al. (48) & 2016 & Guideline \\
\hline \multirow[t]{4}{*}{ Lymphedema surgery } & Markkula et al. (61) & 2019 & Meta-analysis \\
\hline & Siotos et al. (69) & 2018 & Systematic review \\
\hline & Smile et al. (31) & 2018 & Systematic review \\
\hline & Ozturk et al. (66) & 2016 & Systematic review \\
\hline \multirow[t]{4}{*}{ PBMT or LLLT } & Chen et al. (70) & 2019 & Systematic review and meta-analysis \\
\hline & Olsson Möller et al. (27) & 2019 & Systematic review \\
\hline & Baxter et al. (73) & 2017 & Systematic review \\
\hline & Greenlee et al. (29) & 2017 & Review \\
\hline \multicolumn{4}{|l|}{ CAM } \\
\hline \multirow[t]{5}{*}{ Acupuncture } & Liang et al. (6) & 2020 & Systematic review and meta-analysis \\
\hline & Hou et al. (84) & 2019 & Systematic review and meta-analysis \\
\hline & Chien et al. (87) & 2019 & Systematic review and meta-analysis \\
\hline & Zhang et al. (82) & 2019 & Systematic review and meta-analysis \\
\hline & Kim et al. (85) & 2018 & Systematic review \\
\hline \multirow[t]{2}{*}{ Yoga practice } & Wei et al. (95) & 2019 & Systematic review \\
\hline & Rogan et al. (35) & 2016 & Systematic review and meta-analysis \\
\hline Yoga practice, Tai Chi practice & Olsson Möller et al. (27) & 2019 & Systematic review \\
\hline Yoga practice, Qigong, pilates, etc & Panchik et al. (43) & 2019 & Systematic review \\
\hline Reflexology & Wanchai et al. (90) & 2020 & Systematic review \\
\hline
\end{tabular}

MLD: Manual lymphatic drainage; IPC: intermittent pneumatic compression; PBMT: photobiomodulation; LLLT: low-level laser therapy; CAM: complementary alternative medicine. 
Table II. Studies not relevant to BCRL treatment.

\begin{tabular}{|c|c|c|c|}
\hline Topic & Author & Year & Type \\
\hline \multirow{6}{*}{$\begin{array}{l}\text { Epidemiology, comorbidities, } \\
\text { and impact of BCRL }\end{array}$} & Torgbenu et al. (96) & 2020 & Systematic review and meta-analysis \\
\hline & De Vrieze et al. (97) & 2020 & Systematic review \\
\hline & Co et al. (98) & 2019 & Systematic review \\
\hline & Visser et al. (99) & 2019 & Systematic review \\
\hline & Zomkowski et al. (100) & 2018 & Systematic review \\
\hline & Leysen et al. (101) & 2017 & Systematic review and meta-analysis \\
\hline \multirow[t]{4}{*}{ Diagnostic studies } & Abbaci et al. (102) & 2019 & Systematic review \\
\hline & Sierla et al. (103) & 2018 & Systematic review \\
\hline & Burnier et al. (104) & 2017 & Review \\
\hline & Shah et al. (18) & 2016 & Systematic review \\
\hline \multirow[t]{3}{*}{ Radiotherapy } & Liu et al. (105) & 2020 & Systematic review and meta-analysis \\
\hline & Kanda et al. (106) & 2020 & Systematic review and meta-analysis \\
\hline & Sheitelman et al. (107) & 2017 & Systematic review and meta-analysis \\
\hline Chemotherapy & Hugenholtz-Wamsteker et al. (108) & 2016 & Systematic review \\
\hline \multirow{5}{*}{$\begin{array}{l}\text { Diagnostic and therapeutic surgical } \\
\text { procedures causing lymphedema }\end{array}$} & Demiri et al. (109) & 2018 & Systematic review \\
\hline & Parks et al. (110) & 2017 & Systematic review \\
\hline & Bromham et al. (111) & 2017 & Systematic review \\
\hline & Gebruers et al. (112) & 2016 & Systematic review \\
\hline & Han et al. (113) & 2016 & Systematic review and meta-analysis \\
\hline $\begin{array}{l}\text { Safety of hand-surgery following prior } \\
\text { breast cancer treatment }\end{array}$ & Paton et al. (114) & 2020 & Systematic review and meta-analysis \\
\hline \multirow[t]{2}{*}{ Air travel safety in breast cancer patients } & Co et al. (115) & 2018 & Systematic review \\
\hline & Co et al. (116) & 2018 & Systematic review \\
\hline $\begin{array}{l}\text { Generical physical activity recommendation } \\
\text { in people with cancer }\end{array}$ & Shallwani et al. (117) & 2019 & Systematic review \\
\hline
\end{tabular}

radiotherapy and chemotherapy on LYE onset, diagnostic and therapeutic surgical procedures causing LYE, the safety of hand surgery following prior breast cancer treatment, air travel safety in breast cancer patients, and generic physical activity recommendation in people with cancer. Papers defined by the authors as of major scientific importance according to the topics covered are outlined in Table III.

\section{Discussion}

Breast cancer represents the most common cancer among women, with 65.5 cases per 100,000 women $(21,22)$. BCRL represents a social plague and a stigma of cancer. Its treatment is, therefore, crucial in the physical and psychological rehabilitation of women to enhance QoL. Nevertheless, no globally accepted guidelines exist regarding BCRL treatment because of the insufficient level of evidence reached by most published papers due to small sample sizes, heterogeneity of patients and treatments provided, and treatment adherence. A brief discussion regarding the state of the art of BCRL is presented below, taking into consideration every kind of therapy discussed and investigated in the last five years' systematic reviews and meta-analyses. Physical, surgical, medical, and complementary therapies used in BCRL treatment are described below.

Physical therapy. Physical therapy includes the four pillars of Complete or Complex Decongestive Therapy (CDT): manual lymphatic drainage, bandaging and garments, physical exercise, and skincare practice. CTD is considered the first line and the most widely accepted treatment for patients affected by BCRL (20). However, CDT is characterized by a complexity of protocols, thus needing long treatment duration and expensive costs that often discourage patients. CDT internationally accepted best 
practice includes a first phase characterized by an intensive treatment able to decongest the arm through compression bandaging and manual lymph drainage and a second maintenance phase. The patient becomes the main actor of his treatment by wearing compressive garments (23). The mainstays of CDT are listed and discussed below:

Manual lymphatic drainage (MLD) consists of specialized movements that act as a pump on the skin to improve lymph flow and reabsorption. As a result, it reduces the swelling and fibrosis in the affected limb. MLD may be conducted using the Vodder method (24) or Földi's technique (25). It enhances muscle tissue elasticity and beneficially acts on autonomous nervous system activity, increasing parasympathetic tone.

MLD has a beneficial effect but cannot significantly reduce or prevent the risk of long-term LYE, although the literature is not univocal as regards its efficacy $(6,26)$ and its effect seems inconclusive as it reduces arm volume but does not improve subjective symptoms and arm function $(27,28)$. Its failure may be attributed to multiple risk factors and patient's heterogeneity, which may influence outcomes. Nevertheless, some authors advocate its effectiveness in preventing secondary LYE when MLD is applied immediately after breast cancer surgery $(29,30)$, in early phases of BCRL (31), and even in BCRL-affected patients $(32,33)$, by reducing arm volume. However, it is not completely clear if MLD should be part of the therapy after breast cancer surgery and seems to be related to the severity of BCRL (27).

Bandaging and garments reduce fluid formation by means of compression producing counterpressure, reducing the subsequent swelling (29, 34). Standard sleeves have inconclusive effects in reducing arm volume compared to compression bandages or fitted sleeves, which showed beneficial volume reduction (27). Indeed, a standard sleeve is configured not as a treatment modality for the intensive phase of BCRL but as a maintenance tool for the leanest volume, reducing the risk for regaining volume or early stage after the onset BCRL (35). However, the standard sleeves may have a role in preventing additional swelling. Outcomes deriving from their use must be checked regularly (27). On the other hand, bandages have a role in the intensive phase, as they stimulate the resorption of the interstitial lymph fluid and have a more influential role in reducing volume compared to standard sleeves (35). However, the pressure generated by these devices should be carefully assessed by professional therapists.

Kinesio taping can be added to complete decongestive therapy because it generates a low pressure on the skin, improving lymphatic flow, by applying elastic tapes to the skin. Mechanoreceptors simulation and the elastic action seem to influence the lymphatic system $(36,37)$. A recent meta-analysis (38) discussed the role of Kinesio taping role in BCRL. Kinesio taping reduced upper limb volume but, compared to other treatments, no significant difference was evidenced. However, the studies investigated by Kasawara
Table III. Most relevant studies on BCRL treatment according to the Authors' opinion.

\begin{tabular}{lcc}
\hline Author & Year & Topic \\
\hline Jang et al. $(81)$ & 2020 & MLD \\
Rogan et al. (35) & 2016 & Bandage and garments \\
Kasawara et al. $(38)$ & 2018 & Kinesio Taping \\
Rogan et al. $(35)$ & 2016 & IPC \\
Hasenoehrl et al. $(50)$ & 2020 & Physical Exercise \\
Markkula et al. $(61)$ & 2019 & Lymphedema surgery \\
Chen et al. (70) & 2019 & PBMT or LLLT \\
Liang et al. (6) & 2020 & Acupuncture \\
Rogan et al. (35) & 2016 & Yoga practice \\
\hline
\end{tabular}

MLD: Manual lymphatic drainage; IPC: intermittent pneumatic compression; PBMT: photobiomodulation; LLLT: low-level laser therapy.

presented a low methodological quality and different forms of Kinesio taping application (38); thus, it does not allow to conclude the role of Kinesio taping in BCRL treatment.

Intermittent pneumatic compression (IPC) refers to a system composed of an air pump and inflatable auxiliary sleeves or gloves (boots when used for lower limbs) to improve venous and lymphatic circulation. Although IPC effectively reduces BCRL volume in the intensive phase, they cannot be considered a maintenance tool because they only stimulate the drainage in working collectors and do not actually seem to reduce interstitial protein-rich fluid resorption (35).

Physical exercise acts as a muscular pump promoting lymph flow and reducing soft tissue swelling (2). Its effectiveness is also proven in patients receiving adjuvant therapy, as it reduces upper limb volume and diameter and lowers the risk of BCRL $(35,39)$. Devoogdt et al. investigated the effect of exercise with or without MLD association, finding no difference among the groups (40).

One of the most frequent physical exercise obstacles is represented by compliance to programs and the lack of healthcare providers' knowledge regarding training type and prescription.

A systematic metanalysis defined aerobic exercise as "any activity that uses large muscle groups, can be maintained continuously and is rhythmic in nature" (41), like cycling, dancing, hiking, jogging/long-distance running, swimming, and walking. It appeared feasible and safe and did not imply increasing BCRL symptoms or development. Furthermore, it has a beneficial effect in reducing upper limb volume (42), improving upper body strength and endurance, reducing body fat and waist and hip circumference, and increasing muscle mass, associated with psychological and emotional benefits (43).

Nordic walking (NW) defines an aerobic physical activity in which poles support walking; it is low-cost and easy to 
perform and, thus, it is a safe, attractive, and interesting physical exercise for patients affected by breast cancer sequelae (44). It has been demonstrated that NW provides positive changes in BCRL symptoms, reduces extracellular fluid, the circumference of the arm, and the LYE absolute and relative volumes $(27,35,45)$. Furthermore, NW helps in women's perception of BCRL regarding heaviness and tightness and upper limbs disability. However, the most significant difficulty in using NW in BCRL concerns the lack of knowledge of patients and therapists regarding the ground were to perform the exercise, the intensity, and the exercise duration. These concerns make the current studies of low methodological quality and make it challenging to extrapolate exact data regarding NW protocols. Thus, the importance of qualified instructors' interfaces with the physician and the patient and a learning phase of performing NW before they perform it independently. A recent systematic review concluded that a safe prescription to perform NW in women with BCRL might be three times a week exercise, up to 1 hour per session, the intensity of 70$80 \%$ maximum heart rate, and 11-14 of perceived exertion scale (Borg rate) (45). Finally, no evidence exists regarding any adverse effect caused by NW (e.g., falls, commonly described in association with chemotherapy due to toxicity and osteoporosis). Therefore, NW may be considered a safe alternative in BCRL rehabilitation.

Resistance training programs performed on strengthtraining machines have been investigated with regards to their role in BCRL. In addition to determining an improvement in QoL, psychological, cognitive, and social condition, muscle strength, fatigue, pain, and aerobic capacity, resistance training are considered safe as it do not affect the development or worsening of LYE $(33,42,46-48)$, if there is control and progression in training (49), as reported by previous literature (14). Hence, resistance exercise should be considered an additional treatment in cancer patient rehabilitation (48). Several authors depict the resistance exercise as beneficial for BCRL treatment due to its significant reduction $(35,42,43,50,51)$ and increased upper and lower body muscular strength $(27,42,52)$. Standardization of intensity training is difficult due to patient heterogeneity, differences in measurements used and patients' compliance. Few patients report negative effects of resistance exercise. Thus, a resistance training program might be of benefit in BCRL treatment (50).

Aquatic therapy refers to a type of physical exercise that takes advantage of water properties. Aquatic therapy acts as activating muscle pump mechanism and, due to the hydrostatic pressure of water, improves lymphatic circulation. Moreover, it facilitates aerobic exercise, helps muscle strengthening due to the water's natural resistance, and reduces the risk of musculoskeletal injuries while performing the exercise. Furthermore, warm water acts on the imbalance of the autonomous nervous system, increasing parasympathetic activity and decreasing sympathetic tone. A single meta-analysis has been found in literature describing the effect of aquatic therapy in BCRL. However, although no adverse events were reported, no significant benefits of aquatic therapy were evidenced, with no significant difference regarding LYE status and volumetric limb change and physical function of upper limb comparing aquatic therapy to conventional physical exercise and standard care for BCRL. Hence, patients should be addressed to the physical activity to which they can be more compliant (53).

Skincare has a role in preventing infection and subsequent complications (2).

Lymphedema surgery. LYE surgery is an expanding and (relatively) recently introduced tool. It is traditionally considered the last option in BCRL treatment when other measures have failed (54), although early treatment might reduce disease prevention. Indications include inadequate BCRL reduction and patient satisfaction after conservative medical or physical therapy, persistent pain, severely compromised limb function, recurrent lymphangitis, and patient accepting a more invasive treatment as surgery (55). Techniques are distinguished in reductive and reconstructive surgeries:

\section{- Reductive surgery}

o Liposuction is a reductive technique and aims at reducing the arm's volume by removing the excess fibrotic and circumferentially hypertrophied fat tissue through a liposuction cannula (56). As conventional liposuction, postoperative treatment needs the use of life-long compressive garments to prevent a recurrence. Liposuction demonstrated efficacy in moderate-to-severe BCRL (31), but it does not improve lymphatic drainage and may be considered a symptomatic treatment. Surgical resection is an alternative.

\section{- Reconstructive surgery}

o Lymphaticovenular anastomosis (LVA) is a reconstructive method that aims at bypassing the obstruction to lymphatic outflow by creating a direct connection between the lymphatic vessels in the subcutaneous tissue and the veins upstream to the lymphnodes, to redirect the protein-rich fluid (lymph) to the venous circulation $(57,58)$. This way, the scarred and lymphnode deprived axylla is bypassed.

o Lymphatic-lymphatic bypass grafts takes advantage of an intact and unaffected lymphatic vessel to bypass the obstructed area (59). Different dyes are used to detect lymphatic vessels before performing anastomosis and anastomosis patency checks, and follow-up may be conducted through lymphoscintigraphy (55). LVA demonstrated efficacy in advanced BCRL but might also be 
an effective tool in preventing or slowing down disease progression (31).

o Vascularized lymph node transfer (VLNT) aims at reconstructing the resected lymph nodes and at re-connecting lymphatic channels (60). The donor lymph nodes site is often localized in the groin or abdomen, and the harvested nodes are inset into the armpit to replace the native ones. VLNT surgery seems to interrupt a life-long physical and conventional therapy and demonstrated efficacy in advanced BCRL (31).

A recent meta-analysis (2019) (61) compared the efficacy of surgery for prevention and treatment of BCRL by investigating the tissue volume and distribution, the limb composition, and by evaluating the BCRL status through the use of imaging exams (lymphoscintigraphy, lymphangiography, MRI, US, CT scan) (17, 62) after performing LVA $(63,64)$ and VLNT $(65)$. Despite reporting low-certainty evidence in the effectiveness of LVA and VLNT respectively in preventing $\operatorname{BCRL}(63,64)$ and treating stage II LYE (65), the meta-analyses showed that surgery provides encouraging results. Regarding LVA, it emerged that this technique determined a reduction in the incidence of BCRL compared to a non-operative treatment up to 24 months after surgery $(63,64)$. VLNT appeared to be effective in limb volume, pain, heaviness sensation reduction, and function score improvement. Indeed, the VLNT group presented a $57 \%$ reduction of mean limb volume than the control group that received the conventional treatment (18\% limb volume reduction). Furthermore, pain, heaviness sensation reduction, and function score showed improvement after VLNT (65).

Limitations in the paper by Markkula et al. (61), consisted in the fact that none of the included studies discussed longterm complications (cellulitis, lymphangitis, lymphadenitis, skin ulcers, lymphorrea), and only the paper on VLNT by Dionyssiou et al. (65) reported a reduction with regards to short-term complication (seroma, lymphorrea, wound dehiscence, wound infection) in the VLNT group. Furthermore, only three studies were considered eligible for the review; thus, all results were based on a total of 131 patients. Hence, the small sample size does not allow to identify patients' subgroups to identify factors that may be predictive of failure or success of surgical therapy. Finally, no other techniques have been included in the review, and no comparison was made between the effectiveness of a surgical procedure against another. Therefore, further studies are required to determine the efficacy of BCRL surgery as regards prevention and treatment. However, LVA and VLNT surgery are potentially able to decide on beneficial effects in BCRL affected patients.

A previous systematic review regarding VLNT surgery investigated 18 studies (309 limbs, of which 191 BCRL of the upper limbs) and showed that $91 \%$ had improvement in limb circumference, $86 \%$ had improvement in limb volume, and $60 \%$ had improvement of flow at lymphoscintigraphy/ lymphangiography. No donor site persistent LYE was found (66). Hence, VLNT surgery was demonstrated to be a safe and effective tool for BCRL treatment.

Delayed breast reconstruction with autologous tissues deserves special consideration. Indeed, to date, it is unclear whether autologous reconstruction is useful for treating BCRL. A vascularized pedicled or free healthy tissue may provide relief from BCRL $(67,68)$, as discussed in the paper by Siotos. However, the benefit provided by the addition of VLNT to delayed breast reconstruction appears more effective than the microsurgical breast reconstruction alone. This finding may be explained by the flap acts' nodal component, which acts as the largest contributing factor in BCRL improvement. Nonetheless, it has been demonstrated that a flap introduced into a LYE affected area serves as a trigger to the formation of new lymphatic vessels (68), because providing roots for lymph outflow. Finally, all the studies reviewed by Sotos agree that delayed breast reconstruction does not have a role in worsening BCRL (69).

Photobiomodulation therapy. Only a meta-analysis is available as regards photobiomodulation therapy (PBMT) (70). PBMT is a light therapy (wavelength 650-1000 nm), and it is a type of phototherapy deemed capable of improving lymphatic drainage, stimulating lymphangiogenesis, reducing inflammation and related pain (71), improving the wound healing process (72), and finally softening fibrotic tissue (thus its employ in the modulation of scarring process and improving lymphatic flow) (29). A previous systematic review recommended a dose of $1-2 \mathrm{~J} / \mathrm{cm}^{2}$ per point to treat the fibrotic area and volume reduction effectiveness (27). Other authors compared PBMT to sham laser for limb volume and circumference reduction, pain relief and found a more effective action of the first (73). The most recent metaanalysis (70) included nine RCTs that investigated the effects of PBMT on BCRL, but the conflicting results did not allow to clarify the effectiveness of PBMT. Indeed, no statistically significant difference was found in arm circumference, arm volume, grip strength, and pain related to BCRL between the patients who received PBMT and the control groups receiving other treatments. Furthermore, the previous studies' sample size was limited; thus, no significant effect of PBMT in the management of BCRL was found, and no consensus has been reached yet on the PBMT effect.

Medical pharmacological therapy. Medical pharmacological therapy is mostly represented by drug class benzopyrones, which bind to interstitial proteins, thus inducing phagocytosis and proteolysis. Once being fragmented, they can quickly be reabsorbed by venous capillaries. They may 
have a role in reducing interstitial edema, softening the limb affected by BCRL, and reducing infection $(74,75)$. However, they are characterized by hepatotoxicity, and they do not represent the first-line treatment of BCRL. No recent systematic reviews or metanalyses have been found regarding their use in BCRL treatment.

Not enough evidence exists to form a clinical recommendation (29) on therapies such as Cyclo $3{ }^{\circledR}$ Fort (Cyclo $3{ }^{\circledR}$ Fort, Pierre Fabre Medicament Laboratories, Boulogne-Billancourt, France), which is a combination of root extract of the Ruscus aculeatus plant, hesperidin methyl chalcone and ascorbic acid (76), electrotherapy (77), Ginkgo biloba (78), pentoxifylline and vitamin E (79).

Complementary medicine. Acupuncture is part of the traditional Chinese medicine, is based on the regulation of energy pathways and circulation through stimulation of specific points on the body surface, as evidenced by neurophysiological investigations, and has been shown effective and safe in a variety of conditions and treatment-related side effects (80). Acupuncture treatments may also include bloodletting, puncturing and cupping, moxibustion, laser needle and electric stimulation. As results from our review, some studies reported that acupuncture provided a significant decrease in reducing arm circumference when compared to physical exercise $(6,81$ 83 ), but the same conclusion was not found by other authors (84-86). However, it has been reported that acupuncture intervention is safe and tends to improve the efficacy of other BCRL treatments $(84,87)$, compared to the single physical exercise or conventional medicine alone (84).

One of the most critical issues in evaluating the effectiveness of acupuncture is the difference in the technique used that is not always described in these studies and the heterogeneity in assessing the patient's LYE. Indeed, different LYE measurement tools have been used, including the circumference at the height of the elbow or above it, the rim of the most bulging point, the sum of more circumferences calculated at the level of the upper limb, or through the bioimpedance spectrometry measurement. This heterogeneity makes the studies difficult to compare and, therefore, difficult to assess the overall effectiveness of acupuncture treatment. Furthermore, the absence of hidden grouping and blinding method and the reduced sample size produce multiple biases, leading to insufficient evidence of the effectiveness of the acupuncture role in BCRL treatment. Finally, most of the patients who received acupuncture treatment were Asian; thus, no studies represent different ethnic groups $(82,85)$.

Reflexology bases are, to date, not clarified yet. However, theories rely on the direct pressure on a peripheral nerve of the foot in stimulating a corresponding area of the body, providing relief to a specific symptom (88). Reflexology is also based on oxytocin's release, improving the circulation through pressure and the input to the central nervous system that perceives the symptoms (89). Regarding BCRL, reflexology has not enough high-level evidence supporting beneficial or detrimental effects on BCRL, despite no adverse effects reported after reflexology intervention. Reflexology seems to improve quality of life acting on fatigue, nausea, and vomiting, but no substantial evidence is available as regards effects on BCRL because of limited numbers and quality of studies (90).

Yoga practice is considered part of the complementary therapies, but also of physical exercise. It is based on meditation, relaxation, breathing, stretching, and posture control exercises to improve muscles and joints status and range of motion. Yoga interventions may help in reducing pain, swelling, limb volume, and tissue fibrosis $(27,35,91-$ 94). The study by Wei et al. (95) described the effect of different yoga programs, including meditation, warm-up, breathing, exercises, and cooldown, practiced from once to twice a week, with an exercise duration of 60 minutes, for a variable duration from 4 weeks to 6 months of yoga practice. This revision aimed to evaluate if yoga and conventional treatments improved BCRL condition. The measured outcomes were the upper extremity volume, upper limb and grip strength, range of motion, and QoL. Results on BCRL status varied between the studies: some reported that 8-week yoga practice improved LYE and spine mobility but did not report QoL changes; others did not find any change or no significant outcome of the 6-month procedure. Concerns emerging from this investigation are the vast heterogeneity of practice (some studies did not report how the yoga practice was conducted) that make the studies incomparable and not conclusive. It can't be clearly demonstrated that a yoga intervention may provide significant benefits when added to usual treatment. However, developing a standard yoga protocol may reveal that yoga practice, with 1-2 times a week class session and remaining days with home practice, with 60-minute sessions, and extended up to 8 weeks, could lead to a significant improvement of BCRL, reducing swelling, disability and improving joints and muscles status and function and related range of motion, with a final positive impact on QoL. Panchik et al. described the effect of yoga and other physical exercise practice, claiming a decreased swelling and reduction of BCRL related symptoms (43). However, non-traditional forms of exercise should be further investigated to assess their role in BCRL treatment properly.

Alongside yoga practice, Tai Chi intervention had a beneficial effect on emotional wellbeing and upper limb mobility as well, but the investigated studies presented low methodological quality; thus, careful interpretation of these results is mandatory (27).

\section{Limitations}

Almost all conclusions from the studies discussed above should be cautiously taken into account because of the 
insufficient quality of most published papers on BCRL treatment. Indeed, only bandages and IPC showed a substantial beneficial effect in reducing LYE volume in the acute-intensive phase. At the same time, MLD demonstrated effectiveness when immediately applied after breast surgery or in the early stage of BCRL, but not in overt BCRL.

Despite being burdened by difficult compliance to the treatment, physical exercise remains a milestone in BCRL regarding almost all its modalities (aerobic exercise, resistance exercise, aquatic therapy), reduced upper limb volume, improved upper body strength, and does not affect the development or worsening of LYE. Kinesio taping, PBMT, pharmacological therapy and complementary procedures do not show conclusive effectiveness in BCRL treatment, but patients often seek complementary medicine for symptom relief as other therapies are not beneficial. Finally, surgery is considered the last resort. It may be a symptom treatment (liposuction, reducing volume but not improving the drainage), preventing treatment (LVA, reducing $\mathrm{BCRL}$ incidence, improving drainage, useful in BCRL early phase), and curative treatment (VLNT, reducing volume, improving drainage, useful in overt BCRL). At present, no comparison has been made between the effectiveness of a surgical technique against another. Skincare practice is pivotal to prevent infection in association with all concurrent treatments.

This review has certain limitations since the literature search did not include articles before 2016, although many of these and certainly the most important were discussed in the papers examined. Furthermore, the review does not meet the PRISMA criteria for systematic review and included no statistical evaluation because of the impossibility of comparing all the articles discussing substantially different topics. the review is intended as narrative and aims to be an introductory guide for those new to the treatment of BCRL of the upper limb.

\section{Conclusion}

In conclusion, BCRL is still to be considered a challenging issue for breast cancer survivors, and there is not a goldstandard treatment. Furthermore, the lack of clinically globally accepted criteria in evaluating BCRL makes it challenging to evaluate BCRL treatment's effectiveness. As stated by the American Cancer Society and the American Society of Clinical Oncology Breast Cancer Survivorship Care Guideline (48): "It is recommended that primary care clinicians should counsel survivors on how to prevent/reduce the risk of LYE, including weight loss for those who are overweight or obese and should refer patients with clinical symptoms or swelling suggestive of LYE to a therapist knowledgeable about the diagnosis and treatment of LYE, such as a physical therapist, occupational therapist, or LYE specialist." Knowledge about different treatment options deserves diffusion and the role of medical, physical and surgical treatments always considered to improve QoL of breast cancer survivors.

\section{Conflicts of Interest}

All Authors declare that they have no conflicts of interest.

\section{Authors' Contributions}

Study concept and design: PM and SD. Acquisition, analysis, and interpretation of data: PM, SD, SM, VG. Drafting of the manuscript: PM, SD, DP, SM, VG. Critical revision of the manuscript: all authors. All Authors read and approved the final manuscript.

\section{References}

1 DiSipio T, Rye S, Newman B and Hayes S: Incidence of unilateral arm lymphoedema after breast cancer: a systematic review and meta-analysis. Lancet Oncol 14(6): 500-515, 2013. PMID: 23540561. DOI: 10.1016/S1470-2045(13)70076-7

2 Ezzo J, Manheimer E, McNeely ML, Howell DM, Weiss R, Johansson KI, Bao T, Bily L, Tuppo CM, Williams AF and Karadibak D: Manual lymphatic drainage for lymphedema following breast cancer treatment. Cochrane Database Syst Rev (5): CD003475, 2015. PMID: 25994425. DOI: 10.1002/1465 1858.CD003475.pub2

3 Zou L, Liu FH, Shen PP, Hu Y, Liu XQ, Xu YY, Pen QL, Wang $\mathrm{B}, \mathrm{Zhu}$ YQ and Tian Y: The incidence and risk factors of related lymphedema for breast cancer survivors post-operation: a 2-year follow-up prospective cohort study. Breast Cancer 25(3): 309314, 2018. PMID: 29397555. DOI: 10.1007/s12282-018-0830-3

4 Ribeiro Pereira ACP, Koifman RJ and Bergmann A: Incidence and risk factors of lymphedema after breast cancer treatment: 10 years of follow-up. Breast 36: 67-73, 2017. PMID: 28992556. DOI: 10.1016/j.breast.2017.09.006

5 Fu MR, Ridner SH, Hu SH, Stewart BR, Cormier JN and Armer JM: Psychosocial impact of lymphedema: a systematic review of literature from 2004 to 2011. Psychooncology 22(7): 1466-1484, 2013. PMID: 23044512. DOI: 10.1002/pon.3201

6 Liang M, Chen Q, Peng K, Deng L, He L, Hou Y, Zhang Y, Guo J, Mei Z and Li L: Manual lymphatic drainage for lymphedema in patients after breast cancer surgery: A systematic review and meta-analysis of randomized controlled trials. Medicine (Baltimore) 99(49): e23192, 2020. PMID: 33285693. DOI: 10.1097/MD.0000000000023192

7 Sekyere M: Incidence and risk factors of arm lymphedema following breast cancer treatment. Journal of Global Oncology 4(Suppl 2): 213s-213s, 2020. DOI: 10.1200/jgo.18.85800

8 Paskett ED, Dean JA, Oliveri JM and Harrop JP: Cancer-related lymphedema risk factors, diagnosis, treatment, and impact: a review. J Clin Oncol 30(30): 3726-3733, 2012. PMID: 23008299. DOI: $10.1200 /$ JCO.2012.41.8574

9 Szolnoky G, Dobozy A and Kemény L: Towards an effective management of chronic lymphedema. Clin Dermatol 32(5): 685691, 2014. PMID: 25160111. DOI: 10.1016/j.clindermatol. 2014.04.017

10 Doscher ME, Herman S and Garfein ES: Surgical management of inoperable lymphedema: the re-emergence of abandoned 
techniques. J Am Coll Surg 215(2): 278-283, 2012. PMID: 22560317. DOI: 10.1016/j.jamcollsurg.2012.03.020

11 Cooper G and Bagnall A: Prevalence of lymphoedema in the UK: focus on the southwest and West Midlands. Br J Community Nurs Suppl: S6-14, 2016. PMID: 27046432. DOI: 10.12968/bjen.2016.21.Sup4.S6

12 Gebruers N, Verbelen H, De Vrieze T, Coeck D and Tjalma W: Incidence and time path of lymphedema in sentinel node negative breast cancer patients: a systematic review. Arch Phys Med Rehabil 96(6): 1131-1139, 2015. PMID: 25637862. DOI: 10.1016/j.apmr.2015.01.014

13 Harris SR and Niesen-Vertommen SL: Challenging the myth of exercise-induced lymphedema following breast cancer: a series of case reports. J Surg Oncol 74(2): 95-8; discussion 98-9, 2000. PMID: 10914817. DOI: 10.1002/1096-9098(200006)74: 2<95::AID-JSO3>3.0.CO;2-Q

14 Ahmed RL, Thomas W, Yee D and Schmitz KH: Randomized controlled trial of weight training and lymphedema in breast cancer survivors. J Clin Oncol 24(18): 2765-2772, 2006. PMID: 16702582. DOI: $10.1200 / J C O .2005 .03 .6749$

15 Rossi M, Grassi R, Costa R, Di Rosa L, D'Arpa S, Moschella F and Cordova A: Evaluation of the upper limb lymphatic system: A prospective lymphoscintigraphic study in melanoma patients and healthy controls. Plast Reconstr Surg 138(6): 1321-1331, 2016. PMID: 27537229. DOI: 10.1097/PRS.0000000000002763

16 Executive Committee: The diagnosis and treatment of peripheral lymphedema: 2016 consensus document of the International Society of Lymphology. Lymphology 49(4): 170-184, 2016. PMID: 29908550.

17 Yamamoto T, Yamamoto N, Hara H, Mihara M, Narushima M and Koshima I: Upper extremity lymphedema index: a simple method for severity evaluation of upper extremity lymphedema. Ann Plast Surg 70(1): 47-49, 2013. PMID: 21734534. DOI: $10.1097 /$ SAP.0b013e $3182275 \mathrm{~d} 23$

18 Shah C, Arthur DW, Wazer D, Khan A, Ridner S and Vicini F: The impact of early detection and intervention of breast cancerrelated lymphedema: a systematic review. Cancer Med 5(6): 1154-1162, 2016. PMID: 26993371. DOI: 10.1002/cam4.691

19 Berlit S, Brade J, Tuschy B, Hornemann A, Leweling H, Eghardt $\mathrm{V}$ and Sütterlin M: Comparing bioelectrical impedance values in assessing early upper limb lymphedema after breast cancer surgery. In Vivo 26(5): 863-867, 2012. PMID: 22949603.

20 Lasinski BB, McKillip Thrift K, Squire D, Austin MK, Smith KM, Wanchai A, Green JM, Stewart BR, Cormier JN and Armer JM: A systematic review of the evidence for complete decongestive therapy in the treatment of lymphedema from 2004 to 2011. PM R 4(8): 580-601, 2012. PMID: 22920313. DOI: 10.1016/j.pmrj.2012.05.003

21 Ginsburg O, Bray F, Coleman MP, Vanderpuye V, Eniu A, Kotha SR, Sarker M, Huong TT, Allemani C, Dvaladze A, Gralow J, Yeates K, Taylor C, Oomman N, Krishnan S, Sullivan R, Kombe D, Blas MM, Parham G, Kassami N and Conteh L: The global burden of women's cancers: a grand challenge in global health. Lancet 389(10071): 847-860, 2017. PMID: 27814965. DOI: 10.1016/S0140-6736(16)31392-7

22 Global Burden of Disease Cancer Collaboration, Fitzmaurice C, Allen C, Barber RM, Barregard L, Bhutta ZA, Brenner H, Dicker DJ, Chimed-Orchir O, Dandona R, Dandona L, Fleming T, Forouzanfar MH, Hancock J, Hay RJ, Hunter-Merrill R, Huynh C, Hosgood HD, Johnson CO, Jonas JB, Khubchandani J, Kumar
GA, Kutz M, Lan Q, Larson HJ, Liang X, Lim SS, Lopez AD, MacIntyre MF, Marczak L, Marquez N, Mokdad AH, Pinho C, Pourmalek F, Salomon JA, Sanabria JR, Sandar L, Sartorius B, Schwartz SM, Shackelford KA, Shibuya K, Stanaway J, Steiner C, Sun J, Takahashi K, Vollset SE, Vos T, Wagner JA, Wang H, Westerman R, Zeeb H, Zoeckler L, Abd-Allah F, Ahmed MB, Alabed S, Alam NK, Aldhahri SF, Alem G, Alemayohu MA, Ali R, Al-Raddadi R, Amare A, Amoako Y, Artaman A, Asayesh H, Atnafu N, Awasthi A, Saleem HB, Barac A, Bedi N, Bensenor I, Berhane A, Bernabé E, Betsu B, Binagwaho A, Boneya D, Campos-Nonato I, Castañeda-Orjuela C, Catalá-López F, Chiang P, Chibueze C, Chitheer A, Choi JY, Cowie B, Damtew S, das Neves J, Dey S, Dharmaratne S, Dhillon P, Ding E, Driscoll T, Ekwueme D, Endries AY, Farvid M, Farzadfar F, Fernandes J, Fischer F, G/Hiwot TT, Gebru A, Gopalani S, Hailu A, Horino M, Horita N, Husseini A, Huybrechts I, Inoue M, Islami F, Jakovljevic M, James S, Javanbakht M, Jee SH, Kasaeian A, Kedir MS, Khader YS, Khang YH, Kim D, Leigh J, Linn S, Lunevicius R, El Razek HMA, Malekzadeh R, Malta DC, Marcenes W, Markos D, Melaku YA, Meles KG, Mendoza W, Mengiste DT, Meretoja TJ, Miller TR, Mohammad KA, Mohammadi A, Mohammed S, Moradi-Lakeh M, Nagel G, Nand D, Le Nguyen Q, Nolte S, Ogbo FA, Oladimeji KE, Oren E, Pa M, Park EK, Pereira DM, Plass D, Qorbani M, Radfar A, Rafay A, Rahman M, Rana SM, Søreide K, Satpathy M, Sawhney M, Sepanlou SG, Shaikh MA, She J, Shiue I, Shore HR, Shrime MG, So S, Soneji S, Stathopoulou V, Stroumpoulis K, Sufiyan MB, Sykes BL, Tabarés-Seisdedos R, Tadese F, Tedla BA, Tessema GA, Thakur JS, Tran BX, Ukwaja KN, Uzochukwu BSC, Vlassov VV, Weiderpass E, Wubshet Terefe M, Yebyo HG, Yimam HH, Yonemoto N, Younis MZ, Yu C, Zaidi Z, Zaki MES, Zenebe ZM, Murray CJL and Naghavi M: Global, regional, and national cancer incidence, mortality, years of life lost, years lived with disability, and disability-adjusted life-years for 32 cancer groups, 1990 to 2015: A systematic analysis for the Global Burden of Disease study. JAMA Oncol 3(4): 524-548, 2017. PMID: 27918777. DOI: 10.1001/jamaoncol.2016.5688

23 International Society of Lymphology: The diagnosis and treatment of peripheral lymphedema: 2013 Consensus Document of the International Society of Lymphology. Lymphology 46(1): 1-11, 2013. PMID: 23930436.

24 Kasseroller RG: The Vodder School: the Vodder method. Cancer 83(12 Suppl American): 2840-2842, 1998. PMID: 9874409. DOI: 10.1002/(sici) 1097-0142(19981215)83:12b+<2840::aidcncr37>3.0.co;2-5

25 Földi M: Anatomical and physiological basis for physical therapy of lymphedema. Experientia Suppl 33: 15-18, 1978. PMID: 282150.

26 Müller M, Klingberg K, Wertli MM and Carreira H: Manual lymphatic drainage and quality of life in patients with lymphoedema and mixed oedema: a systematic review of randomised controlled trials. Qual Life Res 27(6): 1403-1414, 2018. PMID: 29404923. DOI: 10.1007/s11136-018-1796-5

27 Olsson Möller U, Beck I, Rydén L and Malmström M: A comprehensive approach to rehabilitation interventions following breast cancer treatment - a systematic review of systematic reviews. BMC Cancer 19(1): 472, 2019. PMID: 31109309. DOI: 10.1186/s12885-019-5648-7

28 Shao Y and Zhong DS: Manual lymphatic drainage for breast cancer-related lymphoedema. Eur J Cancer Care (Engl) 26(5), 2017. PMID: 27167238. DOI: 10.1111/ecc.12517 
29 Greenlee H, DuPont-Reyes MJ, Balneaves LG, Carlson LE, Cohen MR, Deng G, Johnson JA, Mumber M, Seely D, Zick SM, Boyce LM and Tripathy D: Clinical practice guidelines on the evidence-based use of integrative therapies during and after breast cancer treatment. CA Cancer J Clin 67(3): 194-232, 2017. PMID: 28436999. DOI: 10.3322/caac.21397

30 Zimmermann A, Wozniewski M, Szklarska A, Lipowicz A and Szuba A: Efficacy of manual lymphatic drainage in preventing secondary lymphedema after breast cancer surgery. Lymphology 45(3): 103-112, 2012. PMID: 23342930.

31 Smile TD, Tendulkar R, Schwarz G, Arthur D, Grobmyer S, Valente S, Vicini F and Shah C: A review of treatment for breast cancer-related lymphedema: Paradigms for clinical practice. Am J Clin Oncol 41(2): 178-190, 2018. PMID: 28009597. DOI: 10.1097/COC.0000000000000355

32 Jeffs E, Ream E, Taylor C and Bick D: Clinical effectiveness of decongestive treatments on excess arm volume and patientcentered outcomes in women with early breast cancer-related arm lymphedema: a systematic review. JBI Database System Rev Implement Rep 16(2): 453-506, 2018. PMID: 29419623. DOI: 10.11124/JBISRIR-2016-003185

33 D'Egidio V, Sestili C, Mancino M, Sciarra I, Cocchiara R, Backhaus I, Mannocci A, De Luca A, Frusone F, Monti M, La Torre $\mathrm{G}$ and RETURN TO BREAST Collaborative group: Counseling interventions delivered in women with breast cancer to improve health-related quality of life: a systematic review. Qual Life Res 26(10): 2573-2592, 2017. PMID: 28623442. DOI: 10.1007/s11136-017-1613-6

34 Tambour M, Holt M, Speyer A, Christensen R and Gram B: Manual lymphatic drainage adds no further volume reduction to Complete Decongestive Therapy on breast cancer-related lymphoedema: a multicentre, randomised, single-blind trial. Br J Cancer 119(10): 1215-1222, 2018. PMID: 30353049. DOI: 10.1038/s41416-018-0306-4

35 Rogan S, Taeymans J, Luginbuehl H, Aebi M, Mahnig S and Gebruers N: Therapy modalities to reduce lymphoedema in female breast cancer patients: a systematic review and metaanalysis. Breast Cancer Res Treat 159(1): 1-14, 2016. PMID: 27460637. DOI: 10.1007/s10549-016-3919-4

36 Cendron S, Paiva L, Darski C and Colla C: Fisioterapia Complexa Descongestiva Associada a Terapias de Compressão no Tratamento do Linfedema Secundário ao Câncer de Mama: uma Revisão Sistemática. Revista Brasileira de Cancerologia 61(1): 49-58, 2020. DOI: 10.32635/2176-9745.RBC.2015v61n1.773

37 Pinheiro M dos S, Godoy AC and Sunemi MM de O: Kinesio Taping associado à drenagem linfática manual no linfedema pós mastectomia: Relato de caso. Fisioter Saúde Func 4: 30-36, 2015.

38 Kasawara KT, Mapa JMR, Ferreira V, Added MAN, Shiwa SR, Carvas N Jr and Batista PA: Effects of Kinesio Taping on breast cancer-related lymphedema: A meta-analysis in clinical trials. Physiother Theory Pract 34(5): 337-345, 2018. PMID: 29308967. DOI: 10.1080/09593985.2017.1419522

39 Furmaniak AC, Menig M and Markes MH: Exercise for women receiving adjuvant therapy for breast cancer. Cochrane Database Syst Rev 9: CD005001, 2016. PMID: 27650122. DOI: 10.1002/14651858.CD005001.pub3

40 Devoogdt N, Geraerts I, Van Kampen M, De Vrieze T, Vos L, Neven P, Vergote I, Christiaens MR, Thomis S and De Groef A: Manual lymph drainage may not have a preventive effect on the development of breast cancer-related lymphoedema in the long term: a randomised trial. J Physiother 64(4): 245-254, 2018. PMID: 30241913. DOI: 10.1016/j.jphys.2018.08.007

41 Wahid A, Manek N, Nichols M, Kelly P, Foster C, Webster P, Kaur A, Friedemann Smith C, Wilkins E, Rayner M, Roberts N and Scarborough P: Quantifying the association between physical activity and cardiovascular disease and diabetes: a systematic review and meta-analysis. J Am Heart Assoc 5(9): e002495, 2016. PMID: 27628572. DOI: 10.1161/JAHA.115.002495

42 Baumann FT, Reike A, Reimer V, Schumann M, Hallek M, Taaffe DR, Newton RU and Galvao DA: Effects of physical exercise on breast cancer-related secondary lymphedema: a systematic review. Breast Cancer Res Treat 170(1): 1-13, 2018. PMID: 29470804. DOI: 10.1007/s 10549-018-4725-y

43 Panchik D, Masco S, Zinnikas P, Hillriegel B, Lauder T, Suttmann E, Chinchilli V, McBeth M and Hermann W: Effect of exercise on breast cancer-related lymphedema: What the lymphatic surgeon needs to know. J Reconstr Microsurg 35(1): 37-45, 2019. PMID: 29935493. DOI: 10.1055/s-0038-1660832

44 Morgulec-adamowicz N, Marszałek J and Jagustyn P: Nordic walking - A new form of adapted physical activity (a literature review). Human Movement 12(2), 2019. DOI: 10.2478/v10038011-0009-7

45 Sánchez-Lastra MA, Torres J, Martínez-Lemos I and Ayán C: Nordic walking for women with breast cancer: A systematic review. Eur J Cancer Care (Engl) 28(6): e13130, 2019. PMID: 31389108. DOI: $10.1111 / \mathrm{ecc} .13130$

46 Hasenoehrl T, Keilani M, Palma S and Crevenna R: Resistance exercise and breast cancer related lymphedema - a systematic review update. Disabil Rehabil 42(1): 26-35, 2020. PMID: 30638093. DOI: 10.1080/09638288.2018.1514663

47 Keilani M, Hasenoehrl T, Neubauer M and Crevenna R: Resistance exercise and secondary lymphedema in breast cancer survivors-a systematic review. Support Care Cancer 24(4): 19071916, 2016. PMID: 26715294. DOI: 10.1007/s00520-015-3068-z

48 Runowicz CD, Leach CR, Henry NL, Henry KS, Mackey HT, Cowens-Alvarado RL, Cannady RS, Pratt-Chapman ML, Edge SB, Jacobs LA, Hurria A, Marks LB, LaMonte SJ, Warner E, Lyman GH and Ganz PA: American Cancer Society/American Society of Clinical Oncology breast cancer survivorship care guideline. J Clin Oncol 34(6): 611-635, 2016. PMID: 26644543. DOI: $10.1200 / J C O .2015 .64 .3809$

49 Montaño-Rojas LS, Romero-Pérez EM, Medina-Pérez C, Reguera-García MM and de Paz JA: Resistance training in breast cancer survivors: A systematic review of exercise programs. Int J Environ Res Public Health 17(18): 6511, 2020. PMID: 32906761. DOI: 10.3390/ijerph17186511

50 Hasenoehrl T, Palma S, Ramazanova D, Kölbl H, Dorner TE, Keilani M and Crevenna R: Resistance exercise and breast cancer-related lymphedema-a systematic review update and meta-analysis. Support Care Cancer 28(8): 3593-3603, 2020. PMID: 32415386. DOI: 10.1007/s00520-020-05521-x

51 Cho Y, Do J, Jung S, Kwon O and Jeon JY: Effects of a physical therapy program combined with manual lymphatic drainage on shoulder function, quality of life, lymphedema incidence, and pain in breast cancer patients with axillary web syndrome following axillary dissection. Support Care Cancer 24(5): 2047-2057, 2016. PMID: 26542271. DOI: 10.1007/ s00520-015-3005-1

52 Nelson NL: Breast cancer-related lymphedema and resistance exercise: A systematic review. J Strength Cond Res 30(9): 2656- 
2665, 2016. PMID: 26840439. DOI: 10.1519/JSC.0000000000 001355

53 Yeung W and Semciw AI: Aquatic therapy for people with lymphedema: A systematic review and meta-analysis. Lymphat Res Biol 16(1): 9-19, 2018. PMID: 28346851. DOI: 10.1089/ lrb.2016.0056

54 Vignes S and Trévidic P: Role of surgery in the treatment of lymphedema. Rev Med Interne 23(Suppl 3): 426s-430s, 2002. PMID: 12162208. DOI: 10.1016/s0248-8663(02)80387-3

55 Campisi C, Bellini C, Campisi C, Accogli S, Bonioli E and Boccardo F: Microsurgery for lymphedema: clinical research and long-term results. Microsurgery 30(4): 256-260, 2010. PMID: 20235160. DOI: 10.1002/micr.20737

56 Brorson $\mathrm{H}$, Svensson $\mathrm{H}$, Norrgren $\mathrm{K}$ and Thorsson $\mathrm{O}$ : Liposuction reduces arm lymphedema without significantly altering the already impaired lymph transport. Lymphology 31(4): 156-172, 1998. PMID: 9949387.

57 Campisi C and Boccardo F: Microsurgical techniques for lymphedema treatment: derivative lymphatic-venous microsurgery. World J Surg 28(6): 609-613, 2004. PMID: 15366754. DOI: $10.1007 / \mathrm{s} 00268-004-7252-4$

58 Nagase T, Gonda K, Inoue K, Higashino T, Fukuda N, Gorai K, Mihara M, Nakanishi $M$ and Koshima I: Treatment of lymphedema with lymphaticovenular anastomoses. Int J Clin Oncol 10(5): 304-310, 2005. PMID: 16247656. DOI: 10.1007/s10147-005-0518-5

59 Lee BB, Laredo J and Neville R: Current status of lymphatic reconstructive surgery for chronic lymphedema: it is still an uphill battle! Int J Angiol 20(2): 73-80, 2011. PMID: 22654468. DOI: $10.1055 / \mathrm{s}-0031-1279685$

60 Becker C, Assouad J, Riquet M and Hidden G: Postmastectomy lymphedema: long-term results following microsurgical lymph node transplantation. Ann Surg 243(3): 313-315, 2006. PMID: 16495693. DOI: 10.1097/01.sla.0000201258.10304.16

61 Markkula SP, Leung N, Allen VB and Furniss D: Surgical interventions for the prevention or treatment of lymphoedema after breast cancer treatment. Cochrane Database Syst Rev 2: CD011433, 2019. PMID: 30779124. DOI: 10.1002/1465185 8.CD011433.pub2

62 Bulley C, Coutts F, Blyth C, Jack W, Chetty U, Barber M and Tan CW: A Morbidity Screening Tool for identifying fatigue, pain, upper limb dysfunction and lymphedema after breast cancer treatment: a validity study. Eur J Oncol Nurs 18(2): 218-227, 2014. PMID: 24246445. DOI: 10.1016/j.ejon.2013.10.006

63 Boccardo FM, Ansaldi F, Bellini C, Accogli S, Taddei G, Murdaca G, Campisi CC, Villa G, Icardi G, Durando P, Puppo F and Campisi C: Prospective evaluation of a prevention protocol for lymphedema following surgery for breast cancer. Lymphology 42(1): 1-9, 2009. PMID: 19499762.

64 Boccardo FM, Casabona F, Friedman D, Puglisi M, De Cian F, Ansaldi F and Campisi C: Surgical prevention of arm lymphedema after breast cancer treatment. Ann Surg Oncol 18(9): 2500-2505, 2011. PMID: 21369739. DOI: 10.1245/s 10 434-011-1624-4

65 Dionyssiou D, Demiri E, Tsimponis A, Sarafis A, Mpalaris V, Tatsidou $G$ and Arsos G: A randomized control study of treating secondary stage II breast cancer-related lymphoedema with free lymph node transfer. Breast Cancer Res Treat 156(1): 73-79, 2016. PMID: 26895326. DOI: 10.1007/s10549-0163716-0
66 Ozturk CN, Ozturk C, Glasgow M, Platek M, Ashary Z, Kuhn J, Aronoff N, Lohman R, Djohan R and Gurunluoglu R: Free vascularized lymph node transfer for treatment of lymphedema: A systematic evidence based review. J Plast Reconstr Aesthet Surg 69(9): 1234-1247, 2016. PMID: 27425000. DOI: 10.1016/j.bjps.2016.06.022

67 Classen DA and Irvine L: Free muscle flap transfer as a lymphatic bridge for upper extremity lymphedema. J Reconstr Microsurg 21(2): 93-99, 2005. PMID: 15739144. DOI: $10.1055 / \mathrm{s}-2005-864841$

68 Yan A, Avraham T, Zampell JC, Aschen SZ and Mehrara BJ: Mechanisms of lymphatic regeneration after tissue transfer. PLoS One 6(2): e17201, 2011. PMID: 21359148. DOI: 10.1371/journal.pone.0017201

69 Siotos C, Hassanein AH, Bello RJ, Sebai ME, Seal SM, Manahan MA, Cooney DS, Cooney CM and Rosson GD: Delayed breast reconstruction on patients with upper extremity lymphedema: a systematic review of the literature and pooled analysis. Ann Plast Surg 81(6): 730-735, 2018. PMID: 29944525. DOI: 10.1097/SAP.0000000000001542

70 Chen HY, Tsai HH, Tam KW and Huang TW: Effects of photobiomodualtion therapy on breast cancer-related lymphoedema: A systematic review and meta-analysis of randomised controlled trials. Complement Ther Med 47: 102200, 2019. PMID: 31780036. DOI: 10.1016/j.ctim.2019.102200

71 E Lima MT, E Lima JG, de Andrade MF and Bergmann A: Lowlevel laser therapy in secondary lymphedema after breast cancer: systematic review. Lasers Med Sci 29(3): 1289-1295, 2014. PMID: 23192573. DOI: 10.1007/s10103-012-1240-y

72 Posten W, Wrone DA, Dover JS, Arndt KA, Silapunt S and Alam M: Low-level laser therapy for wound healing: mechanism and efficacy. Dermatol Surg 31(3): 334-340, 2005. PMID: 15841638. DOI: $10.1111 / \mathrm{j} .1524-$ 4725.2005.31086

73 Baxter GD, Liu L, Petrich S, Gisselman AS, Chapple C, Anders JJ and Tumilty S: Low level laser therapy (Photobiomodulation therapy) for breast cancer-related lymphedema: a systematic review. BMC Cancer 17(1): 833, 2017. PMID: 29216916. DOI: 10.1186/s12885-017-3852-X

74 Harris SR, Hugi MR, Olivotto IA, Levine $M$ and Steering Committee for Clinical Practice Guidelines for the Care and Treatment of Breast Cancer: Clinical practice guidelines for the care and treatment of breast cancer: 11. Lymphedema. CMAJ 164(2): 191-199, 2001. PMID: 11332311.

75 Cheifetz O, Haley L and Breast Cancer Action: Management of secondary lymphedema related to breast cancer. Can Fam Physician 56(12): 1277-1284, 2010. PMID: 21375063.

76 Cluzan RV, Alliot F, Ghabboun S and Pascot M: Treatment of secondary lymphedema of the upper limb with CYCLO 3 FORT. Lymphology 29(1): 29-35, 1996. PMID: 8721977.

77 Belmonte R, Tejero M, Ferrer M, Muniesa JM, Duarte E, Cunillera $\mathrm{O}$ and Escalada F: Efficacy of low-frequency lowintensity electrotherapy in the treatment of breast cancer-related lymphoedema: a cross-over randomized trial. Clin Rehabil 26(7): 607-618, 2012. PMID: 22172923. DOI: 10.1177/026921551 1427414

78 Cluzan RV, Pecking AP, Mathiex-Fortunet $\mathrm{H}$ and Léger Picherit E: Efficacy of BN165 (Ginkor Fort) in breast cancer related upper limb lymphedema: a preliminary study. Lymphology 37(2): 47-52, 2004. PMID: 15328756. 
79 Gothard L, Cornes P, Earl J, Hall E, MacLaren J, Mortimer P, Peacock J, Peckitt C, Woods M and Yarnold J: Double-blind placebo-controlled randomised trial of vitamin $\mathrm{E}$ and pentoxifylline in patients with chronic arm lymphoedema and fibrosis after surgery and radiotherapy for breast cancer. Radiother Oncol 73(2): 133-139, 2004. PMID: 15542159. DOI: 10.1016/j.radonc.2004.09.013

80 Joshi $\mathrm{N}$ and Araque H: Neurophysiologic basis for the relief of human pain by acupuncture. Acupunct Electrother Res 34(3-4): 165-174, 2009. PMID: 20344884. DOI: $10.3727 / 036012909803861022$

81 Jang S, Ko Y, Sasaki Y, Park S, Jo J, Kang NH, Yoo ES, Park NC, Cho SH, Jang H, Jang BH, Hwang DS and Ko SG: Acupuncture as an adjuvant therapy for management of treatment-related symptoms in breast cancer patients: Systematic review and meta-analysis (PRISMA-compliant). Medicine (Baltimore) 99(50): e21820, 2020. PMID: 33327222. DOI: 10.1097/MD.0000000000021820

82 Zhang X, Wang X, Zhang B, Yang S and Liu D: Effects of acupuncture on breast cancer-related lymphoedema: a systematic review and meta-analysis of randomised controlled trials. Acupunct Med 37(1): 16-24, 2019. PMID: 30845813. DOI: 10.1136/acupmed-2018-011668

83 Zhan Jing L: Clinical observation of abdominal acupuncture combining with upper limb functional exercise in treatment of patients with breast cancer-related upper limb lymphoedema. Chin J Woman Child Health Res 28: 570-572, 2017.

84 Hou W, Pei L, Song Y, Wu J, Geng H, Chen L, Wang Y, Hu Y, Zhou J and Sun J: Acupuncture therapy for breast cancer-related lymphedema: A systematic review and meta-analysis. J Obstet Gynaecol Res 45(12): 2307-2317, 2019. PMID: 31608558. DOI: $10.1111 /$ jog. 14122

85 Kim TH, Kang JW and Lee MS: Current evidence of acupuncture for symptoms related to breast cancer survivors: A PRISMA-compliant systematic review of clinical studies in Korea. Medicine (Baltimore) 97(32): e11793, 2018. PMID: 30095640. DOI: 10.1097/MD.0000000000011793

86 Bao T, Iris Zhi W, Vertosick EA, Li QS, DeRito J, Vickers A, Cassileth BR, Mao JJ and Van Zee KJ: Acupuncture for breast cancer-related lymphedema: a randomized controlled trial. Breast Cancer Res Treat 170(1): 77-87, 2018. PMID: 29520533. DOI: 10.1007/s10549-018-4743-9

87 Chien TJ, Liu CY and Fang CJ: The effect of acupuncture in breast cancer-related lymphoedema (BCRL): A systematic review and meta-analysis. Integr Cancer Ther 18: 1534735419866910 , 2019. PMID: 31387468. DOI: $10.1177 / 1534735419866910$

88 Luo Z, Wang L, Sikorskii A and Wyatt G: Healthcare service utilization and work-related productivity in reflexology intervention for advanced breast cancer women. Support Care Cancer 27(8): 2837-2847, 2019. PMID: 30552595. DOI: $10.1007 / \mathrm{s} 00520-018-4592-4$

89 Modern Institute of Reflexology. Available at: http:// reflexologyinstitute.com/faq_student1.php [Last accessed on March 20, 2021]

90 Wanchai A and Armer JM: A systematic review association of reflexology in managing symptoms and side effects of breast cancer treatment. Complement Ther Clin Pract 38: 101074, 2020. PMID: 31783340. DOI: 10.1016/j.ctcp.2019.101074

91 Parshad O: Role of yoga in stress management. West Indian Med J 53(3): 191-194, 2004. PMID: 15352751
92 Ross A and Thomas S: The health benefits of yoga and exercise: a review of comparison studies. J Altern Complement Med 16(1): 3-12, 2010. PMID: 20105062. DOI: 10.1089/acm.2009.0044

93 Narahari SR, Aggithaya MG, Thernoe L, Bose KS and Ryan TJ: Yoga protocol for treatment of breast cancer-related lymphedema. Int J Yoga 9(2): 145-155, 2016. PMID: 27512322. DOI: 10.4103/0973-6131.183713

94 Narahari SR, Ryan TJ, Mahadevan PE, Bose KS and Prasanna $\mathrm{KS}$ : Integrated management of filarial lymphedema for rural communities. Lymphology 40(1): 3-13, 2007. PMID: 17539459.

95 Wei CW, Wu YC, Chen PY, Chen PE, Chi CC and Tung TH: Effectiveness of yoga interventions in breast cancer-related lymphedema: a systematic review. Complement Ther Clin Pract 36: 49-55, 2019. PMID: 31383443. DOI: 10.1016/j.ctcp.2019.05.004

96 Torgbenu E, Luckett T, Buhagiar MA, Chang S and Phillips JL: Prevalence and incidence of cancer related lymphedema in low and middle-income countries: a systematic review and metaanalysis. BMC Cancer 20(1): 604, 2020. PMID: 32600278. DOI: 10.1186/s 12885-020-07079-7

97 De Vrieze T, Nevelsteen I, Thomis S, De Groef A, Tjalma WAA, Gebruers $\mathrm{N}$ and Devoogdt N: What are the economic burden and costs associated with the treatment of breast cancer-related lymphoedema? A systematic review. Support Care Cancer 28(2): 439-449, 2020. PMID: 31656987. DOI: 10.1007/s00520-01905101-8

98 Co M, Lee A and Kwong A: Cutaneous angiosarcoma secondary to lymphoedema or radiation therapy - a systematic review. Clin Oncol (R Coll Radiol) 31(4): 225-231, 2019. PMID: 30738715. DOI: $10.1016 /$ j.clon.2019.01.009

99 Visser J, van Geel M, Cornelissen AJM, van der Hulst RRWJ and Qiu SS: Breast cancer-related lymphedema and genetic predisposition: a systematic review of the literature. Lymphat Res Biol 17(3): 288-293, 2019. PMID: 30358483. DOI: 10.1089/ lrb.2017.0083

100 Zomkowski K, Cruz de Souza B, Pinheiro da Silva F, Moreira GM, de Souza Cunha N and Sperandio FF: Physical symptoms and working performance in female breast cancer survivors: a systematic review. Disabil Rehabil 40(13): 1485-1493, 2018. PMID: 28325132. DOI: 10.1080/09638288.2017.1300950

101 Leysen L, Beckwée D, Nijs J, Pas R, Bilterys T, Vermeir S and Adriaenssens N: Risk factors of pain in breast cancer survivors: a systematic review and meta-analysis. Support Care Cancer 25(12): 3607-3643, 2017. PMID: 28799015. DOI: 10.1007/s00520-0173824-3

102 Abbaci M, Conversano A, De Leeuw F, Laplace-Builhé C and Mazouni C: Near-infrared fluorescence imaging for the prevention and management of breast cancer-related lymphedema: A systematic review. Eur J Surg Oncol 45(10): 1778-1786, 2019. PMID: 31221460. DOI: 10.1016/j.ejso. 2019.06.009

103 Sierla R, Dylke ES and Kilbreath S: A systematic review of the outcomes used to assess upper body lymphedema. Cancer Invest 36(8): 458-473, 2018. PMID: 30289283. DOI: 10.1080/073579 07.2018 .1517362

104 Burnier P, Niddam J, Bosc R, Hersant B and Meningaud JP: Indocyanine green applications in plastic surgery: A review of the literature. J Plast Reconstr Aesthet Surg 70(6): 814-827, 2017. PMID: 28292569. DOI: 10.1016/j.bjps.2017.01.020

105 Liu L, Yang Y, Guo Q, Ren B, Peng Q, Zou L, Zhu Y and Tian $\mathrm{Y}$ : Comparing hypofractionated to conventional fractionated 
radiotherapy in postmastectomy breast cancer: a meta-analysis and systematic review. Radiat Oncol 15(1): 17, 2020. PMID: 31952507. DOI: 10.1186/s13014-020-1463-1

106 Kanda MH, da Costa Vieira RA, Lima JPSN, Paiva CE and de Araujo RLC: Late locoregional complications associated with adjuvant radiotherapy in the treatment of breast cancer: Systematic review and meta-analysis. J Surg Oncol 121(5): 766776, 2020. PMID: 31879978. DOI: $10.1002 /$ jso.25820

107 Shaitelman SF, Chiang YJ, Griffin KD, DeSnyder SM, Smith BD, Schaverien MV, Woodward WA and Cormier JN: Radiation therapy targets and the risk of breast cancer-related lymphedema: a systematic review and network meta-analysis. Breast Cancer Res Treat 162(2): 201-215, 2017. PMID: 28012086. DOI: $10.1007 / \mathrm{s} 10549-016-4089-0$

108 Hugenholtz-Wamsteker W, Robbeson C, Nijs J, Hoelen W and Meeus M: The effect of docetaxel on developing oedema in patients with breast cancer: a systematic review. Eur J Cancer Care (Engl) 25(2): 269-279, 2016. PMID: 25348689. DOI: 10.1111/ecc.12261

109 Demiri E, Dionyssiou D, Tsimponis A, Goula OC, Mulothridis P, Pavlidis L, Spyropoulou GA and Foroglou P: Donor-site lymphedema following lymph node transfer for breast cancerrelated lymphedema: a systematic review of the literature. Lymphat Res Biol 16(1): 2-8, 2018. PMID: 29087763. DOI: 10.1089/lrb.2017.0043

110 Parks RM and Cheung KL: Axillary reverse mapping in N0 patients requiring sentinel lymph node biopsy - A systematic review of the literature and necessity of a randomised study. Breast 33: 57-70, 2017. PMID: 28282588. DOI: 10.1016/ j.breast.2017.02.019

111 Bromham N, Schmidt-Hansen M, Astin M, Hasler E and Reed MW: Axillary treatment for operable primary breast cancer. Cochrane Database Syst Rev 1: CD004561, 2017. PMID: 28052186. DOI: 10.1002/14651858.CD004561.pub3
112 Gebruers N and Tjalma WA: Clinical feasibility of Axillary Reverse Mapping and its influence on breast cancer related lymphedema: a systematic review. Eur J Obstet Gynecol Reprod Biol 200: 117-122, 2016. PMID: 27019287. DOI: 10.1016/ j.ejogrb.2016.03.014

113 Han C, Yang B, Zuo WS, Zheng G, Yang L and Zheng MZ: The feasibility and oncological safety of axillary reverse mapping in patients with breast cancer: a systematic review and metaanalysis of prospective studies. PLoS One 11(2): e0150285, 2016. PMID: 26919589. DOI: 10.1371/journal.pone.0150285

114 Paton M, Kovar A and Iorio ML: An evaluation of safety and patient outcomes for hand surgery following prior breast cancer treatment: Establishing new recommendations in lymphedema. Plast Reconstr Surg 145(2): 459-467, 2020. PMID: 31985641. DOI: $10.1097 / \mathrm{PRS} .0000000000006438$

115 Co M, Ng J and Kwong A: Air travel safety in postoperative breast cancer patients: A systematic review. Clin Breast Cancer 18(5): e813-e817, 2018. PMID: 29859745. DOI: 10.1016/j.clbc. 2018.05.003

$116 \mathrm{Co} \mathrm{M}, \mathrm{Ng} \mathrm{J}$ and Kwong A: Air travel and postoperative lymphedema-a systematic review. Clin Breast Cancer 18(1): e151-e155, 2018. PMID: 29157874. DOI: 10.1016/j.clbc.2017. 10.011

117 Shallwani SM, King J, Thomas R, Thevenot O, De Angelis G, Aburub AS and Brosseau L: Methodological quality of clinical practice guidelines with physical activity recommendations for people diagnosed with cancer: A systematic critical appraisal using the AGREE II tool. PLoS One 14(4): e0214846, 2019. PMID: 30969981. DOI: 10.1371/journal.pone.0214846

Received April 6, 2021

Revised June 3, 2021

Accepted June 7, 2021 